\title{
Varied Assessments Used to Measure Students' Achievement in Introduction to Literature Class
}

Nurul Ain

\begin{abstract}
This paper reported types of assessments and assessment practices used in Introduction to Literature (ITL) class. Looking at the context and the purpose of the assessment, the principles of classroom learning are to be applied in planning, constructing and administering the tests. The test was also constructed to contain a representative sample of the course, the relationship between the test items and the course objectives to keep up with the content validity. The test has two forms of assessment as dealt in learning contract that are spoken and written forms. The results of students' assessment can be categorized into several categories: the first category is the students who have good achievement both in spoken and written performances; the second one is for category which the students have great range of different between spoken and written performances; the third category is the students who have the little range of differences between spoken and written performances; and the last category is the students who have got fair achievement both in spoken and written performances.
\end{abstract}

\section{Introduction}

Assessment is a skill that does not come easy to the practitioners. Classroom teachers usually have problems in constructing, administering, and using assessment procedures and techniques. Traditionally, EFL teachers have tried to develop 
assessment products. Teachers of English as a Foreign Language, working with alternatives in assessment need training in how to assess their students' performance through conferencing, reading and learning performance's tasks and. All these forms require in-depth knowledge of and adequate training in the dynamics of holistic scoring, cooperative learning portfolio, team evaluation, and design of the evaluation profile.

Assessment procedures cannot be separated and should not be separated from the teaching learning process. In fact, the principle of the trainer-relatedness of teaching and assessment is a major characteristic of all new EFL/ESL teaching methodologies (Oller, 1987; Nunan, 1988). Therefore, classroom tests should reflect teaching objectives, teaching methods, teaching activities, and exercises and teaching materials.

Introduction to Literature (ITL) as one of the courses in English Department curriculum. This course was designed to make the students know that literature is a useful tool for encouraging them to draw on their own experience, feeling, and opinions, and develop not only students; language skills and their imaginative sensibilities, but also develop students' character, build emotional maturity, and equip new critical facilities as well. For the materials of ITL, a good literary text can be effectively used to produce language consciousness, and raise the awareness of appreciate and create beauty of language. It helps the students to become more actively involved both intellectually and emotionally in learning (Lazuar, 1992:24). Materials selection should be on the basis of whether is in line with the major interest of the students. The unique materials and process of teaching learning in Literature class give consequences to the forms of assessments. 


\section{Literature Review}

\section{Language Testing}

For language testing purposes, we must consider language ability within an interactional framework of language use. We present a view of language use as that focuses on the interactions among areas of language ability, topical knowledge, and affective schemata, on the other hand, and how these interact with characteristics of the language use setting, or test task, on the other.

The characteristics of individuals-language users or test takers-include personal characteristics, topical knowledge, affective schemata, and language ability. Language ability consists of language knowledge and strategic competence, or metacognitive strategies. Language knowledge, which is information specific to language use that is stored in memory, includes both organizational knowledge and pragmatic knowledge.

Strategic competence consists of meta-cognitive strategies, which are executive processes that enable language users to engage in goal setting, assessment, and planning. Assessment involves three aspects:

1. assessing the characteristics of the language use task to determine the desirability and feasibility of accomplishing it,

2. assessing the elements of topical and language knowledge to determine whether the necessary elements are available, and

3. monitoring and evaluating the correctness and appropriateness of response-utterance or interpretation- in accomplishing the chosen task 


\section{Test}

A test should test what the writer wants it to test. It should be valid. Test validity presupposes that the writer can be explicit about what is to be tested and takes steps to ensure that the test reflects realistic use of the particular ability to be measured. As far as possible a test should limit itself to measuring only what it is intended to test.

Construct validity pertains to the meaningfulness and appropriateness of the interpretations that we make on the basis of the test scores. The validity of these interpretations cannot simply be asserted, but must be demonstrated. Test validation is the on-going process of demonstrating that a particular interpretation of test scores is justified, and involves providing evidence justifying that interpretation. The justification that we need to provide is evidence of construct validity, or evidence that the test score reflects the area of language ability we want to measure, and very little else.

This kind of validity depends on a careful analysis of the language being tested and of the particular course objectives. The test should be so constructed as to contain a representative sample of the course, the relationship between the test items and the course objectives always being apparent. There is strong tendency, especially in multiple-choice testing, to test only those areas of the language which lend themselves readily to testing. Many test of phonology, for instance, concentrated in the past on testing phoneme discrimination rather than the more important features of stress and intonation: one cannot help but suspect the reason for this was simply that phoneme tests were easier to construct than items testing stress and intonation.

When embarking on the construction of a test, the test writer should first draw up a table of test specifications, describing in very clear and precise terms the particular 
language skills and areas to be included in the test. If the test or sub-test being constructed is a test of grammar, each of the grammatical areas should then be given a percentage weighting (e.g. the future simple tense 10 per cent, uncountable nouns 15 per cent, relative pronouns 10 per cent, etc) as touched upon previously. If the test or subtest concerns reading, then each of the reading sub-skills should be given a weighting in a similar way (e.g. deducing word meanings from contextual clues 20 per cent, searchreading for specific information 30 per cent, reading between the lines and inferring 12 per cent, etc.). it scarcely matters what the total percentage is: the important point is that the test writer has attempted to quantify and balance the test components, assigning a certain value to indicate the importance of each component in relation to the other components in the test. In this way, the test should achieve content validity and reflect the component skills and areas which the test writer wishes to include in the assessment.

\section{Oral test}

We need to establish the important features of spoken interaction that might be built into our language tests so that we have a readily available framework to help us in their construction. We will consider in some detail those features of spoken interaction that available theory would suggest including in a test.

A three-part framework is proposed, covering: the operations (activities/skills) that are involved in spoken interaction such as informational routines, e.g. telling a story, and the improvisational skills that might be called into play when the performance of these routines breaks down, e.g. requesting clarification; the conditions under which the tasks are performed, e.g. time constraints, the number of people 
involved and their familiarity with each other; and the quality of output, the expected level of performance in terms of various relevant criteria, e.g. accuracy, fluency, intelligibility.

The purpose of developing such a framework is to offer a tentative checklist of points in each of its three parts that might usefully be considered in the construction of language tests which lay claim to be assessing the construct of spoken language interaction. Although we may lack a fully comprehensive and accessible working model of language use, we should be able to describe the performance conditions, operations and criteria for assessing quality of output that are appropriate for our tests. The analysis of a test task in terms of these features would indicate the degree to which it reflected the attributes of the activity in real life that it was meant to replicate the categories included in the framework are hypothesized as being important, but only in the light of empirical research will it be possible to state with confidence which are the most important variables.

\section{Written test}

The writing skills are complex and sometimes difficult to teach, requiring mastery not only of grammatical and rhetorical devices but also of conceptual and judgmental elements. The following analysis attempts to group the many and varied skills necessary for writing good prose into five general components or main areas.

- Language use: the ability to write correct and appropriate sentences;

- Mechanical skills: the ability to use correctly those conventions peculiar to the written language (e.g. punctuation, spelling); 
- Treatment of content: the ability to think creatively and develop thoughts, excluding all irrelevant information.;

- Stylistic skills: the ability to manipulate sentences and paragraphs, and use language effectively;

- Judgment skills: the ability to write in an appropriate manner for a particular purpose with a particular audience in mind, together with an ability to select, organize, and order relevant information.

Tasks requiring the students to act the part of another person are often avoided as it is felt they are less realistic and communicative. However, this is usually far from being the case. It is useful to provide the students not only with details about they are supposed to be and the people about.

Although the former task is one which students may conceivably have to perform in real life, the latter task will result in far more realistic and natural letters from the students simply because the specific details make the task more meaningful and purposeful.

\section{Method}

The students that become subjects of this research are the ones who join in Introduction to Literature (ITL). There are 139 students that are divided into 5 classes, class A, class B, class C, class D, and class E. all those classes will be taken since this research focus is to describe the students; result of varied tests given to them to measure their proficiency in ITL course. 
Collecting data to answer the research problems will be done by giving test to students as the subjects of research. They have twice of test: mid-test and final test. Both of them have two kinds of retests, oral test and written test. Through these tests, it will be found the results of the students; proficiency. So the data are the scores of students 'oral and written tests.

Since this research focused on carried test and their result, so the instrument in this research is tests. There are two kinds of tests - oral and written tests- which will be given to students twice in a semester. They are mid semester and final test.

For middle test, the students present orally their idea about the character analysis of short story chosen in front of the class. The cores cover the students; idea, fluency and language. After that, they will be given a week to collect the written form of their analysis presented in front of class. It is regarded as the written test. The indicator of scoring is content-idea- and technical writing related with organizing idea and grammar. At last the scores of oral combined with the scores of written to the score of middle test.

For final test, the students also have two kinds of test, oral and written ones. They will be tested orally by lecturer after they collect the written analysis regarded as the written test. It is such face to face test and the questions will be about their idea about the char acre they choose from written drama or script of movies. The indicator of scoring is the same with middle test. So the score for final test are score of oral and written test. 


\section{Results and Discussions}

\section{Findings on varied assessment used in ITL class}

Referring to the research problem stated, the data found, a) related to how varied assessment used divided into two period of the learning process in ITL class. They are the first period (from beginning until middle of the learning process and after middle until final of the learning process).

Findings on assessment used from beginning till middle of the learning process in

\section{ITL class}

Introduction to literature course as one of the literature group of courses in English Department STAIN Kediri is a very important because it is the prerequisitelesson to the other literature courses. The students should pass this lesson if they will take the other courses; English Prose, English drama and English poetry. As the introduction course of literature, the materials of ITL cover the comprehending about literature through the various literary works, included short story and drama.

This course started with the contract of learning that deals between the lecturer and the students. It covers the materials, strategy, and the assessment. How to run these classes rely on the students' activities from class presentation until writing the paper.

Assessment used for the first period of the learning process covers all the activities the students have to be done. There are some process the students should do to get the middle test score.

a. The students have to make a group of two. Each of group should find a short story with such of limitation such as its length, its topic, and the short story must 
be in English of course. The short story should refer to the Islamic figure of the Islamic history.

b. They discuss in a group of two to make a summary of the story they choose. They also divide the job because each of them should take one main character of the story.

For the activities, the students should be divided into two kinds of assessment based on their performance in doing the task. They are written and spoken activities.

1. Written assessment

For getting the score of written, the students should do some activities:

a. $\quad$ Each of the members in a group analyzes one main character as explained in learning contract. These analyses are about main character "personality and his/her conflict of the story they choose.

b. The students should consult with the lecturer of the main character personality analysis and main characters conflict analysis.

c. After that, the students revise as the lectures' suggestion. At last, they find out the paper and collect it as one of the middle test score.

The focus of the scoring of the written assessment covers the content and the form of writing. The content included the students' idea of the analysis about main characters' personality and main characters' conflict. For the form of writing, the students should write a good paragraph, consisting of the existence of the topic sentences and the development sentences; unity of the sentences they used and the transition words of the bridge among the sentences.

2. Spoken assessment 
As dealt, in the learning contract about middle test score that is it consists of two scores; written and spoken scores, the students should also perform the activities for getting spoken scores besides the written one. There are some activities that the students should do relating with the spoken assessment. They are:

a. As the students did for the written one, the students should present the written analysis in front of the class. Each member of the group presents his analysis for a limited timefor about 15 minutes.

b. After the presentation has been finish, the students should also handle the questions from the other friends related with what they have presented in a class discussion.

c. The lecturers observed the students' presentation and giving their scores for the spoken one.

The criteria for giving scores of their presentation covers the content and the language performance. For the content point, the scoring is the same with what the criteria for writing, that is the idea of the students' analysis about main characters' personality and main characters' conflict. The language performance covers their fluency in speaking, and their pronunciation.

After the students do all the learning process of the first period and do both written and spoken assessment they had their middle test scores. It combines the scores both from written and spoken then divided into two and the result is the middle test scores. 


\section{Findings on assessment used after middle till final of the learning process in ITL}

class

As discussed in learning contract at the beginning of the course, the students' activities for the second period to get final test scores also had been dealt. They should do some steps of the process, they are: a) the students also make a group of two to do to carry out the tasks. They can keep the group of first period or they can change the member of the group. Then they should find a drama script or movie script. It can be the stories from the western, b) the students discuss the movie with the friends in a group then they make summary together and divide the jobs about main characters of the story. They should choose one main character that is different with the other member of the group.

For the activities, the students should be divided into two kinds of assessment based on their performance in doing the task. They are written and spoken activities.

1) Written assessment

For getting the score of written, the students should do some activities:

a. Each of the members in a group analyzes one main character as what they did for getting mid test scores of the written one.These analyses areabout main character "personality and his/her conflict of the story they choose.

b. The students should not consult with the lecturer because they had it from the first period. Then they directly collect the paper after they have finished in analyzing the main characters' personality and the main characters' conflict of the movie script. Based on this paper the students will get oral test from the lecturer. 
c. After doing the analysis, each of the members bundled his own analysis and collect to the lecturer.

The focus of the scoring of the written assessment covers the content and the form of writing. The content included the students' idea of the analysis about main characters' personality and main characters' conflict. For the form of writing, the students should write a good paragraph, consisting of the existence of the topic sentences and the development sentences; unity of the sentences they used and the transition words of the bridge among the sentences.

2) Spoken Assessment

After the students collect the paper as the written assessment, they faced the oral test. It is such as interview between the lecturer and the students. In a group, each of the groupshad been tested by giving them questions about what they have written in the paper. The score of this oral test covers the content and the language used.

For the content point, the scoring is the same with what the criteria for writing that is the idea of the students' analysis about main characters' personality and main characters' conflict. The language performance covers their fluency in speaking, and their pronunciation.

After the students do all the learning process of the first period and do both written and spoken assessment they had their middle test scores. It combines the scores both from written and spoken then divided into two and the result is the middle test scores. 


\section{The Students' Achievement Both in Spoken and Written Assessment in ITL Class}

The ending of learning process in ITL class is the evaluation of students' performances. It has two forms of assessment as dealt in learning contract that are spoken and written forms. After all the results of students' assessment got, there are varied result from both spoken and written that can be categorized into several criterias. There are four categories: the first category is the students who have good achievement both in spoken and written performances; the second one is for category which the students have great range of different between spoken and written performances; the third category is the students who have the little range of differences between spoken and written performances; and the last category is the students who have got fair achievement both in spoken and written performances.

The category of students who have good achievement both in spoken and written performances

After data about students' assessment collected and identified, one of the categories shows students have good achievement both spoken and written one for the more it still can be divided into two groups. They are the students have got very good achievement and good achievement both in spoken and written assessment. The result can be seen in the table below.

Table A.1: The students' achievement are very good both in spoken and written achievement.

\begin{tabular}{|c|l|r|r|}
\hline & Students' Name & Spoken & Written \\
\hline & Cresita Diana Putri & 86 & 86 \\
\hline & Farida Tuzzulfa & 86 & 88 \\
\hline & Imamatul Udhma & 90 & 93 \\
\hline & NilaYudi Astiti & 86 & 89 \\
\hline & Fithria Fakhrunnisa & 94 & 88 \\
\hline
\end{tabular}




\begin{tabular}{|l|l|l|l|}
\hline & Leni Mariyana & 86 & 87 \\
\hline & Nikmatul Asroriya & 90 & 89 \\
\hline & Nurin Umi Habibah & 88 & 86 \\
\hline & Rima Khasanah & 86 & 90 \\
\hline & Nur Sinta Windia & 93 & 90 \\
\hline & Nurin Novaliya & 89 & 88 \\
\hline & Dewi Nur Maya & 94 & 88 \\
\hline & Nina Kurniasih & 90 & 86 \\
\hline & Lailatul Mahmudah & 93 & 89 \\
\hline & Emilda Ratna Rahayu & 86 & 90 \\
\hline
\end{tabular}

Table A.2: The students' achievements are good both in spoken and written achievement.

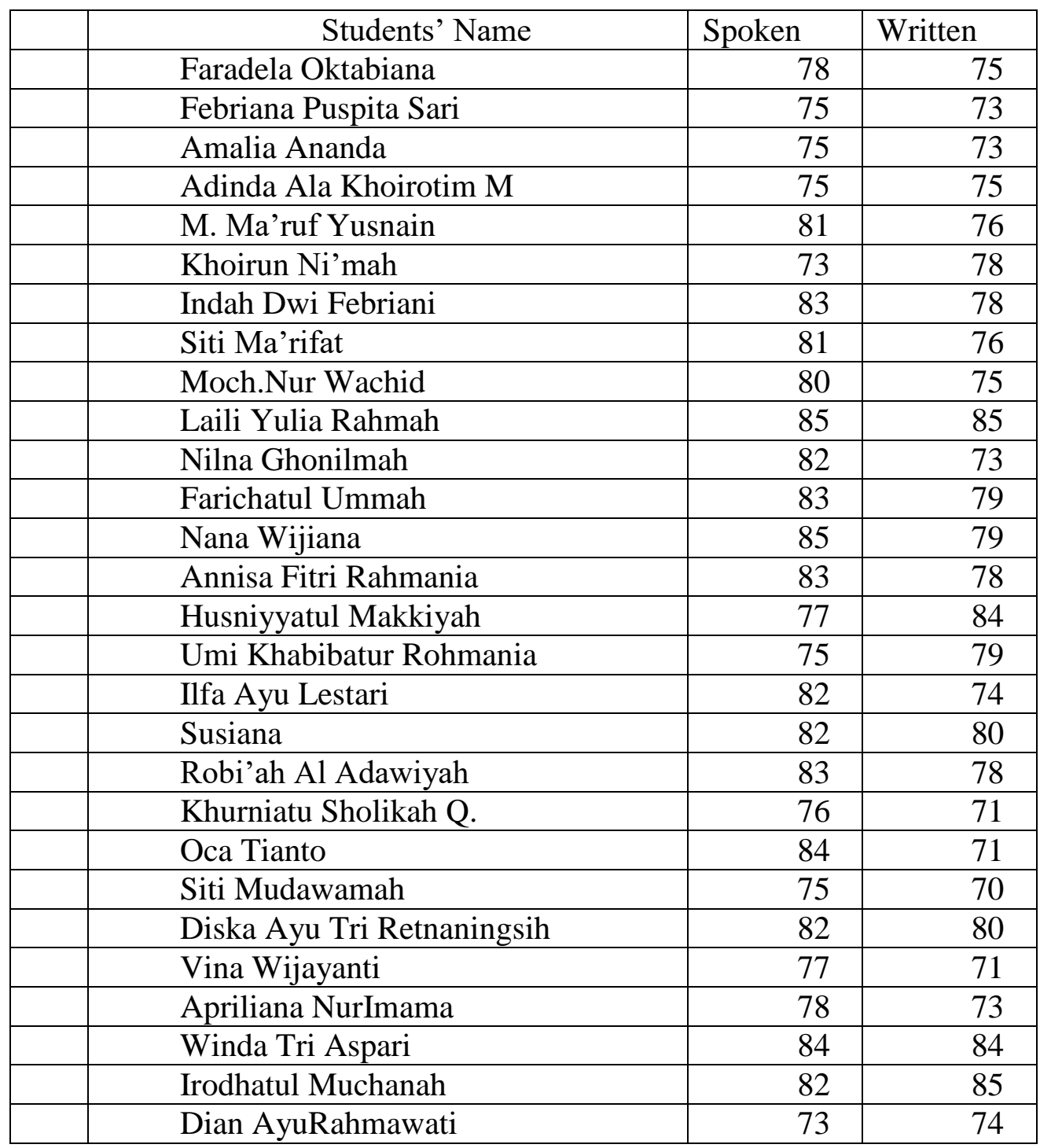




\begin{tabular}{|l|l|r|r|}
\hline & Winda Sari Rahayu & 79 & 71 \\
\hline & NurIzatul Maula & 83 & 85 \\
\hline & Moch.Lutfi Amin & 85 & 75 \\
\hline & Ira Rahmawati & 73 & 83 \\
\hline & Titin Samsiyah Tri Rahayu & 75 & 80 \\
\hline & Nadyatus S. & 78 & 73 \\
\hline & Afilian Hanik Santoso & 81 & 72 \\
\hline & Nurul Farikhatus Sholihah & 85 & 85 \\
\hline & Irchamna Kamila & 85 & 76 \\
\hline & Ali Jazuli & 85 & 71 \\
\hline & Miftahun Ni'mah & 79 & 74 \\
\hline & Moh.Nofal & 83 & 75 \\
\hline & Iffatur Rohmah & 84 & 82 \\
\hline & Vika Wulandari & 77 & 71 \\
\hline & Suhaila Jehtae & 82 & 80 \\
\hline & Affaf Cheleng & 82 & 72 \\
\hline
\end{tabular}

\section{The category of students who have great range of different between spoken and}

\section{written performances}

The data also shows another variant of students' achievement as the second category it is the students who have great different. it is the students "spoken achievement is a very good and the students written one is a fair".

Table B: The students' achievements are very good in spoken and fair in written.

\begin{tabular}{|c|l|c|c|}
\hline & \multicolumn{1}{|c|}{ Students' Name } & Spoken & Written \\
\hline 1 & M. HasanBasori & 87 & 70 \\
\hline 2 & AliefJauharMujadid & 86 & 65 \\
\hline 3 & Ahmad NailiSyahruMulya & 87 & 70 \\
\hline
\end{tabular}

The category of students who have the little range of differences between spoken and written performances

The result of the students' achievement shows that many of them have just a little differences between their spoken and written performances. There are two group forms 
in this category; the first is the range of criteria is between very good and good; and the second between good and fair.

a) the range of the students' achievement difference is in very good and good criteria.

Table C.1.a The students' achievements are very good in spoken and good in written.

\begin{tabular}{|c|c|c|}
\hline Students' Name & Spoken & Written \\
\hline Mohamad Pascal Fakhriz & 88 & 84 \\
\hline RohmahKaruniawati S. & 90 & 85 \\
\hline AldiahRosmalina P. & 89 & 81 \\
\hline NurinaMahfudhoh & 86 & 84 \\
\hline LyaPuspaRini & 88 & 84 \\
\hline SitiUswatunKhasanah & 88 & 79 \\
\hline M. SirojutTholibin & 91 & 84 \\
\hline EndahAsriNurHidayah & 90 & 84 \\
\hline DiahMardianaPramesti & 88 & 84 \\
\hline AsaurRosyidah & 89 & 76 \\
\hline Tri WahyuSetyaningsih & 88 & 85 \\
\hline KhusnatulLaily & 87 & 78 \\
\hline HizbiyatulMahfudhoh & 91 & 79 \\
\hline KunnyMasrurroh & 87 & 85 \\
\hline AlekWijaya Yusuf & 88 & 72 \\
\hline Martina & 89 & 72 \\
\hline JuliSastikasari & 86 & 74 \\
\hline Norma Kumala Al Imama & 86 & 83 \\
\hline RismaNoviantika & 87 & 76 \\
\hline AhmadaRafi'atulMui'zah & 89 & 85 \\
\hline Suheniati & 86 & 80 \\
\hline RatnaMustikaBelapati & 88 & 75 \\
\hline SelaFatmala & 89 & 80 \\
\hline DheaRizqiLailiRahma & 93 & 84 \\
\hline EkaEtikasari & 87 & 77 \\
\hline EllyMasruroh & 98 & 85 \\
\hline AyuMeilinda & 86 & 73 \\
\hline Rif'atulMillah & 92 & 80 \\
\hline AnisatulBahiroh & 89 & 71 \\
\hline SitiMunadiroh & 86 & 80 \\
\hline KhauzahMillati & 86 & 74 \\
\hline Nurul Hidayati & 90 & 82 \\
\hline
\end{tabular}


Table C.1.b The students' achievements are good in spoken and very good in written.

\begin{tabular}{|c|l|c|c|}
\hline No. & \multicolumn{1}{|c|}{ Students' Name } & Spoken & Written \\
\hline 1 & HimaNurulHidayah & 85 & 92 \\
\hline 2 & DewiKhasanah & 85 & 89 \\
\hline 3 & Ira FitriAnggraini & 80 & 89 \\
\hline 4 & IzzahNazilatunNi'mah & 83 & 89 \\
\hline 5 & EviMufidaturRohmatika & 81 & 86 \\
\hline 6 & Ira FitriAnggraini & 80 & 89 \\
\hline
\end{tabular}

b) the range of the students' achievement difference is in good and fair criteria.

Table C2a. The students' achievements are good in spoken and fair in written.

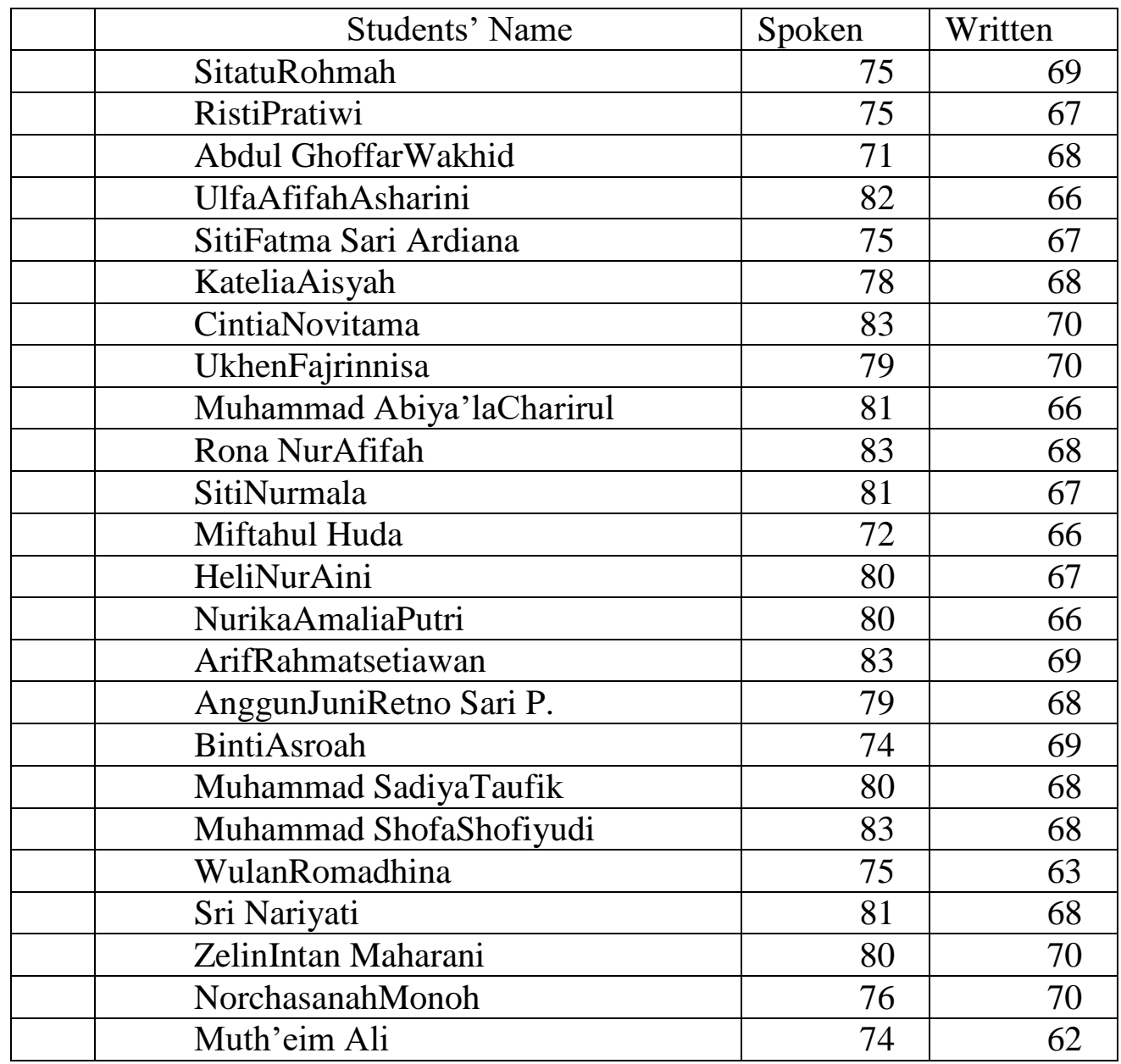


Table C2b. The students' achievements are fair in spoken and good in written.

\begin{tabular}{|c|l|c|c|}
\hline No. & \multicolumn{1}{|c|}{ Students' Name } & Spoken & Written \\
\hline 1 & Rusnani Alee & 70 & 77 \\
\hline
\end{tabular}

\section{The category of students who have fair achievement both in spoken and written performances}

The last category shows that there is a few students having fair criteria for their achievements.

Table D. The students' achievements are fair both in spoken and written achievement.

\begin{tabular}{|c|l|c|c|}
\hline No. & \multicolumn{1}{|c|}{ Students' Name } & Spoken & Written \\
\hline 1 & M. Rio Pradana & 69 & 63 \\
\hline 2 & Suwasti & 67 & 65 \\
\hline 3 & HasanFauzi & 65 & 66 \\
\hline 4 & M. A'thofulIhsan & 60 & 67 \\
\hline
\end{tabular}

\section{Conclusion}

This study has reported varied assessment used for doing assessment of learning in the Introduction to Literature (ITL) class. There are two types of tests used -the written test and the oral test. Both tests were used to give a fuller description of the students understanding of the course content (by analysing and presenting characters of the selected short story) and also of the students ability to express their idea in spoken language through the presentation stage and in written form during the analysis stage. 


\section{References}

Bachman, Lyle F. and Adrian S. Palmer.1996Language Testing in Practice: Designing and Developing Useful Language Tests. Oxford: Oxford University Press.

Heaton, J.B. 1988. . Writing English Language Tests.. New York: Longman Group Limited.

Nun, Xie.Criteria for Selection of Literary Text in Second Language Teaching.English Edu.Vol 6 No. 1Tahun 2006

Wahyana, Anton. English as a Foreign Language: How should it be assessed? .English Edu.Vol 6 No. 1Tahun 2006

Weir, C.J. 1993.Understanding and Developing Language Tests.1Unpublished Great Britain: Prentice Hall Ltd. 